\title{
Electron Microprobe Analysis
}

National Cancer Institute

\section{Source}

National Cancer Institute. Electron Microprobe Analysis. NCI Thesaurus. Code C78873.

A technique that quantifies the $x$-rays emitted after ionization by a finely focused beam of electrons directed onto a flat polished specimen. 